\title{
THE ROLE OF FOREIGN LANGUAGE TEACHING IN ENHANCING STUDENTS' INTERCULTURAL COMPETENCE
}

\author{
Kifah Amara ${ }^{1^{*}}$ \\ ${ }^{1}$ Near East University Graduate School of Educational Sciences, PhD Candidate \\ kifahamara@yahoo.com \\ Correspondence: kifahamara@yahoo.com
}

\begin{abstract}
This study emphasizes the critical role of foreign language teaching in enhancing students' intercultural competence, as a means of expanding their future opportunities in an increasingly multicultural and diverse world. Foreign language classes may provide unique opportunities for delivering a plurilingual, multicultural setting utilizing the cultural elements in the course content and course materials as well as the personal experiences of the teacher in the classroom. To that end, more attention is needed to foreign language teacher preparation and training. As multiculturalism is a significant feature of European communities, this study sought to investigate and analyze the related policies, strategies and practices in Europe, since Paris declaration 2015, in order to determine actions have been taken to address those needs. This qualitative study is based on document analysis of the European Educational Policy documents released mainly by the European Commission and the Council of Europe. The results of the analysis showed that foreign language education has presented along with intercultural education in the vast majority of European educational policies as a dominant component within the context of integration and promote social cohesion, as well as increase competitiveness and employability. The study has implied a number of implications highlighted some potential gaps that may be diminish the effectiveness of these policies, pushing towards more empirical research on the influence of EU policies on national level actions.
\end{abstract}

Keywords: Foreign language Teaching, Intercultural competence, multilingual competence, plurilingual, multicultural setting

\section{Introduction}

In an open and globalized world, Heterogeneity has increasingly shaped the face of many societies worldwide, which entails several implications at all levels. That revealed the need to deal with diversity in a constructive manner in order attain social cohesion.

In Europe, Diversity is a foregone conclusion, so the past two decades have witnessed rapid movements in terms of policies aimed at integrating migrants into society to fulfil their needs and deepen their affiliation of European identity, However, While Europe prides its pluralistic identity, there is still a disparity between EU member states in responding to the requirements of pluralism, which has resulted in inequality and some forms of exclusion. Evidence shows that migrant students so far lagging behind compared with their native-born counterparts and they are more likely to leave schools in early age (Eurydice, 2019), according to the OECD's PISA survey of 2015, The proportion of underachieved immigrant students is greater than of native-born students in many EU participated countries (OECD, 2016). This may indicate that as yet many countries, including developed countries, are still far from achieving the global aspiration of Sustainable Development Goal 4 to ensure 
"inclusive and equitable quality education and promote lifelong learning opportunities for all” ( United Nations, 2017).

Thus, faster and intensive collective work is needed at all levels in order to elevate the progress towards ambition, European countries likewise strive to preserve their Pluralism, through promoting more effective inclusive education system, by shifting the perceptions against diversity to be seen as an opportunity rather than a deficit, and towards inclusion to be treated as a right in lieu of a burden, to so doing, a share amount of interest should be placed on enhancing intercultural dialogue, consequently reinforce mutual understanding among EU citizens, to enjoy their shared European identity.

In this research, plurilingualism is assumed as a means to enhance pluralculturalism and intercultural communication while both of them are key competences to promote ultimately a better integration of all citizens from different backgrounds, therefore, the intention was to investigate how European educational policies reflect the relationship between the two competences, more specifically, the main purpose of the study is to identify the role of foreign language teaching in enhancing intercultural competence through the lenses of EU related policies. To this end document analysis approach was conducted to analyze the content of European educational policies in their relevance to intercultural and plurilingual education. The scope of the study limited to official policy documents released by European commission, council of Europe, European Union and other official bodies in the EU, after Paris declaration 2015, with the aim of emphasizing the recent policies and how they influence on intercultural and multilingual education.

\subsection{Diversity and Inclusion in the European Educational Policy}

The protracted debate around diversity and inclusion in Europe likewise in other parts of the world has been characterized by unprecedented massive flow of immigrant in recent few decades, which brought to the Surface new demands concerning the integration of these migrants into social, political and economic fabric. Researchers see migration as one of the most challenging feature of contemporary education systems, which requires acting proactively (Gogolin, 2011). Thus, integration of migrants is the common theme of most educational policies in Europe, Cullen (1996) explained how the educational policies have shifted from migration notion into citizenship across three stages of development since postwar period, where the first stage focused on merely access to education, while the second supported the teaching of the migrant's mother tongue, and the third stage emphasized the role of education in facilitating equal opportunities for all children as well as promoting pluralism.

Consequently, the early EU policy on the integration of migrants who are TCNs in 2002, was intended to promote equity and diversity, and the policies followed after have concentrated on the same motive, (Faas, Hajisoteriou \& Angelides, 2014) concluded that The common rationale of European policies concerning migrants is to better integrate them into society as well as to increase their competitiveness in the labour market.

Other voices suggested that educational policies should be inclusive for all children rather than solely supplementary intervention targeting particular individuals, (Feliu, Barcons \& Gelabert, 2016) this suggestion is consistence with the findings of a study which revealed that the most prominent change in the cultural diversity related rhetoric during the last decade, was the transformation of the language of that discourse to be directed towards the inclusion of all students regardless of their backgrounds, adding a new dimension to educational policies represented in intercultural education (Sikorskaya, 2017). 
Similarly, Staiger (2009) argued that even though the discourse about citizenship has stuck around the same mottos, however, it has implied promoting cultural dialogue among all citizens including conflicting entities. On the contrary, some claimed that intercultural dialogue has been referred to in EC principles as immigrants' matter to express their obligations (e.g., "respecting basic EU values, participating in the labour market, having basic knowledge of the host society's language, history, and institutions") (Agustin, 2012).

Chalier (2009) has reported that in spite of the recognition of cultural diversity as "the fourth pillar of sustainable development", different forms of discrimination and rejection are witnessed in many regions, therefore, effective actions should be taken to influence intercultural policies at national, local and regional level to promote intercultural dialogue and combating all forms of discrimination.

On the other side of the spectrum lies multilingualism, which is often accompanied with interculturalism as a means to enhance mutual understanding as well as boosting individual competitiveness and economic growth (Climent 2016), thence, No wonder that both of them has inherited in most EU educational policies.

While The EU's motto 'united in diversity' denotes the fundamental role of linguistic and cultural diversity in realizing the European project, however, this diversity is considered as the most critical challenge for European's unity (Toggenburg, 2004) Therefore, a common sense of affiliation to European identity based on linguistic and cultural diversity should be promoted, in order to confront all forms of extremism (King, 2018).

\subsection{Interculturalism and Multilingualism; Terminology and Definitions}

In an increasingly globalized world, the (Learning to live together) becomes a persistent need, this entail the possession of effective communication competences and mutual understanding, especially in societies with a wide range of cultural and linguistic diversity, intercultural dialogue is a paramount.

It is worth mentioning that there are a number of concepts that can be encountered in this regard, therefore, the focus will be placed on the concepts contained in the current study.

Multiculturalism: refers to "the natural state of society that cannot but be diverse, namely multilingual, multi-ethnic, multireligious, etc." (Council of Europe 2012). This may reflect the notion that many diverse entities coexist in the same social fabric. While interculturalism connotes reciprocal relationship between cultures, and based on " the readiness to make the encounter with other cultures productive, to gain greater awareness of one's own culture, to be able to relativise one's own culture and explore new ways of coexistence and cooperation with other cultures" (Council of Europe 2012).

Arslan and Rata (2013) argued that interculturalism and all other relevant terms are synonyms of multiculturalism, this is consistence with (Meer \& Modood 2011) who demonstrated that all advantages attributed to interculturalism are features of multiculturalism too.

Whereas, some limited the difference between the two concepts to the geographical aspect, where multicultural education is commonly in the United States while in Europe intercultural education is preffered (Hill 2007).

Sikorskaya (2017) pinpointed that in the contrast with what has been advocated of the declining of multiculturalism, However, EU educational policies still promoting a multicultural approach wherein "others" in many countries are still perceived as a minority in 
their curricula. Which indicate the absence of consensus on the concept within the European Union (Agustín, 2012).

The council of Europe differentiates between the two concepts, whereby Multilingualism is perceived as owning two or more languages, while plurilingualism reflects "the ability to use languages for the purposes of communication and to take part in intercultural interaction, where a person, viewed as a social agent has proficiency, of varying degrees, in several languages and experience of several cultures." (Council of Europe (2001). Similarly Coste and Lee (2009) argued that pluralingualism goes beyond the functional limits of language to initiate a base for living together, thus it expresses the capability of "conveying the diversity of individual situations spread out over a multi-dimensional, dynamic and evolving set of continuous variations." adding that knowledge in the original language and in the host language is incorporated into a single repertoire.

Based on the aforementioned definitions, it can be concluded that plurilingualism might be intertwined with interculturalism, in terms that both of them represents the communicative dimension of the language. Whereas multilingualism likewise multiculturalism envisioning a state of a person or a society.

Many scholars has simplified the distinct between the two concepts to be considered as a terminological choice, Jeoffrion et al. (2014) questioned the authenticity of the term (plurilingualism ) in English language, inferred to neglecting the term in the dictionaries of the English language (Ortega \& Piccardo 2018).

However, there is a consensus that plurilingualism has conceptualized to reflect the complex role of the language within a divergence context, focuses on "the relationships between the languages an individual speaks, the underlying linguistic mechanisms and cultural connotations, the personal linguistic and cultural trajectory as well as the persons' attitude toward language diversity, stressing openness, curiosity, and flexibility." (Piccardo, 2017).

Therefore, plurilingual education emphases the importance of developing pluralingual and intercultural competence as a way to live together (Council of Europe 2007).

It is noteworthy that the terms multilingual and plurilingual will be used interchangeably, while intercultural term will be preferred for the purpose of the current study.

\section{Method}

In this qualitative study, the document analysis approach was adopted in order to review and analyze the related documents released by various official European bodies, such as; the Council of Europe, the European Union, the European Commission, and Ministers of Education.

Therefore, the content of (fifteen) documents (legislations) and (seventeen) official publications, has been analyzed using the inductive approach, then categorized into themes, related to the central question of the study, considering differences, similarities andlor contradiction between documents,

The study focused on the following research questions:

- What are the characteristics of European educational policies that addressed intercultural and multilingual competences? 
- How does the European education policy reflect the role of foreign language teaching in enhancing intercultural competence?

\section{Results and Discussion}

Data was collected by analyzing the content of the documents within the chronological limits from 2015 until 2019, with an emphasis on tracking intercultural competence in these documents in its relation to foreign language teaching, with the aim of determining whether or not they have been focused on, and related to each other, as well as examining their context.

The resultant data yielded three topics related to the research questions, whereby the texts of the policy were interpreted in light of the subject of the study, while some of these texts were attached in the tables as an appendix and referred to them as necessary.

The findings based on the research question "what are the characteristics of European educational policies that addressed intercultural and multilingual competences?" are given in the following.

\subsection{Interculturalism and Plurilingualism in the European Context}

The debate around intercultural education can be understood within several contexts that reinforce policies and practices towards positive change on the ground. These policies can be contextualized within socioeconomic, political and global context.

In Paris declaration (2015), the European Union education ministers reiterated their determination to continue working to enhance the intrinsic values of freedom of thought and expression, social inclusion and respect for others, as well as preventing and tackling discrimination in all its forms among future generations in order to preserve the pluralistic of European societies, therefore, they call for intensive work to safeguard these values and embed them profoundly into the educational system.

This can be achieved at local and European level, whereby the EU role will be instrumental to support coordination in identifying the common challenges, and enhancing collaboration to overcome them. To so doing a greater emphasis should be placed on exchange experiences, and sharing the best ideas and practices throughout the European Union, in order to achieve the intended objectives wherein the promotion of social inclusion through strengthening intercultural competencies at the heart of these objectives.

Many actions followed Paris declaration, The 2016 Eurydice study on the implementation of the Paris declaration, revealed that most countries have adopted different policies to realize agreed objectives. However, the vast majority of policies have focused on ensuring the acquisition of social, civic and intercultural competences more than other objectives such as enhancing critical thinking and media literacy or promoting the education and training of disadvantaged children and young people (Eurydice, 2016).

In Improving and modernising education 2016, the European Commission has stressed the need to maintain high-quality and inclusive education systems, to this end, a set of actions were taken including the announcement of the New Skills Agenda for Europe, review the 2006 framework of key competences for lifelong learning as well as supporting initial teacher education and in -service professional development, in order to disseminate the EU common values, In addition to drafting. 
In November 2017, the (Strengthening European Identity through Education and Culture) framework sets out a vision for the European Education Area by 2025 with the view of empowering education and culture as fundamental factors for "job creation, economic growth and social fairness as well as a means to experience European identity in all its diversity" In this framework, the Council called for a recommendation on promoting common values, inclusive education, and the European dimension of teaching.

The role of multicultural and multilingual competence in this framework is conspicuously emphasized, as the integration requires acquiring good language competences, therefore Multilingualism is pivotal in addressing cultural diversity in Europe, meanwhile it remains one of the most substantial challenges. In responding to this need, a crucial action was recommended aiming at "improving language learning in Europe, setting out a benchmark that by 2025 all young Europeans finishing upper secondary education have a good knowledge of two languages in addition to their mother tongue(s)."

In addition, the prominent role of teachers in providing and imparting these skills, competences, and knowledge in students' life is highly recognized, thus, teachers capabilities should be elevated through more focusing on teachers education and preparation, encouraging mobility and experience exchange among educators across Europe, through Erasmus programme and the "eTwinning" network which are examples of actions taken towards this end.

It becomes obvious that intercultural dialogue is at the heart of all initiatives aiming at promoting mobility within European commission states, and multilingualism is paving the way for effective intercultural dialogue, so both competencies are linked to each other, and acquiring them is essential for teachers and students alike, which will ultimately enhance social cohesion, and more strengthening of European identity.

The same motive has profoundly represented in (social dimension of Europe) that sought to empower citizens to create strong societies, aiming at harnessing the diverse features of European societies to gain more prosperity in socioeconomic, political and global context (E.C206,2017:32) so that educational policies strive to conform to unprecedented rapidly changes and advancements across the globe.

It is worth mentioning that while European societies could be considered as the most equal and inclusive societies worldwide, they still need to equal distribution of the benefits of globalization, within this context, interculturalism and plurilingualism are partake in achieving equity into all segments of the society, opening prospects towards more employability and competitiveness locally and globally.

We can see how the heterogeneity of European societies played a decisive role in determining educational policies in general and those relevant to intercultural and plurilingual dimensions in particular, aiming at ensuring effective inclusion of migrants into schools and society, as well as raising individual competitiveness and employability, in addition to realizing European identity as a leading influential global nation.

Puzic (2008) argued that the wider political agenda is likely to have more influence on educational policies concerning cultural diversity, more than any other possible factors, while the recent EU level educational initiatives seem to be guided by the intent to achieve better integration of migrants into society and into the labour market (Faas, Hajisoteriou \& Angelides, 2014). 
Sikorskaya (2017) has asserted that there is a substantial shift in intercultural discourse in educational policies from targeting minority and immigrant students to students in general regardless their backgrounds.

Hence, the importance of Intercultural education becomes increasingly acknowledged as an effective intervention to meet global, political and social demands, which can ensure more prosperity for individuals and the whole society likewise (Hoffmann \& Briga 2018).

The findings based on the research question "How the European educational policies reflect the role of foreign language teaching in enhancing intercultural competence?" are given as follows.

\subsection{The relationship between foreign language teaching and intercultural education}

The Communication on School development and excellent teaching for a great start in life, has defined multilingual and intercultural competences as key competences that should be focused on to address students' needs and to respond to their diversity, evidence shows that schools that embrace linguistic and cultural diversity across their school population and support integration have a positive effect on all children's ability to learn. However, this is not the case in all cities and regions where a large proportion of newly arrived migrant students still need to be supported with relevant language programmes. Research indicates that immigrant students and their families encountering communication barriers with school staff, although many initiatives were implemented to promote inclusion, so far they have had limited impact on the ground (Pena 2019).

A significant share of interest in the interrelationship between foreign language teaching and intercultural communication has been evident in several educational policies;(see table 2) The updated strategic framework for European cooperation in education and training has emphasized the role of education and training in equipping all students with intercultural competences that enable them to communicate effectively with others and become active citizenship, as a result, a new benchmark was proposed that: "at least $80 \%$ of pupils in lower secondary education should be taught at least two foreign languages.” (CoE, 2018:9,14).

After the aforementioned benchmark in (Strengthening European Identity through Education and Culture) which is related to upper secondary education; the new one seeks to provide teaching in at least two foreign languages from an early age, this may indicate on one hand that policies in this regard are consistent and being followed up, On the other hand, it can be inferred that the problem still exists and there is a pressing need to deal with it. The argument is that educational policies and instruments are not enough to promote multilingual and intercultural education, in the absence of harmony among the European Union countries on the implementation of these policies (Beacco 2013).

In council recommendation On a comprehensive approach to the teaching and learning of languages, apparent view of foreign language teaching is expressed, whereas the language plays a decisive role in promoting reciprocal understanding and mobility as well as fostering productivity and competitiveness, it has been envisaged that foreign language teaching alongside with intercultural education is the starting point towards a European Education Area by 2025, moreover, it is the multilingual competency that will enable all citizens to gain the fruit of globalization, Thus, further improvement of language teaching is essential at all levels of schooling.

So that a lifelong development of multilingual competences can be achieved, therefore, the recommendations stated in this policy document, reflect the needs towards that aspiration, by 
focusing on learning outcomes and improving language learning in compulsory education through raising language-awareness in school education ( CoE 2019).

Stimulating multilingual learning environment is a paramount, However, education system in Europe is still lagging in this regard, teachers and school leaders need to be supported through relevant training and professional development, in order to transform their perceptions on language diversity to be seen as an opportunity rather than a challenge. In addition to the need of supportive learning resources and convenient curricula as well as innovative pedagogies and assessment techniques (CoE 2019).

Therefore, the language dimension is a constant feature of all educational policies aiming at effective inclusion of migrant students. A variety of research (Eurydice, 2019; Achaeva et al., 2018) showed that migrant students across the EU perform less than their peers, and are likely to drop out from schools prematurely, as a result of social exclusion due to cultural and linguistic factors in addition to socioeconomic disadvantage (Janta \& Harte, 2016).

One of the approaches to integrate newly arrived migrant students is providing them with intensive language classes within the school day in which so called preparatory or reception classes. However, EU member states vary in the provision and the content of these preparatory classes (Eurydice, 2019). Moreover, whereas some researchers pointed out that little proof has been provided on the efficacy of these "pull-out programmes", on the contrast they might deepen their isolation

"Building a supportive school culture" is the ideal way to deal with diversity, allowing all students to better engage in school life (Lee; Ostwald; Gu, 2019).

Intercultural dialogue is often perceived as a means to achieve social cohesion, 'multicultural' and 'intercultural' are sometimes used interchangeably, some countries address it as a cross-curricular theme, while other countries represent it as a topic through specific initiatives and projects. However, in both ways, it is considered as a response to cultural heterogeneity in European societies. (Eurydice, 2019:141) such diversity should be seen as a valuable source that can be harnessed, particularly multilingualism that is central to promoting mutual understanding throughout Europe.

In most European educational policies Language and culture have been twinned whether in objectives or actions, plurilingual alongside with pluracultural competence is fundamental in achieving effective social cohesion, the European Council in its conclusions of 14 December 2017 highlighted that "education and culture are key to building inclusive and cohesive societies, and to sustaining our competitiveness."

Evidence shows that language can be taught fruitfully side by side with intercultural education (Giorgis, 2018) whereby plurilingual and pluricultural are correlated constituting the communicative language competence, where the full range of languages available to the person are fused.

In addition, both competences are key to reinforce lifelong learning, and they are significantly interrelated, given that languages competences connote a historical and intercultural dimension, while the intercultural competence implies a good knowledge of languages, Moreover, both of them are a prerequisite for citizenship competence.

Thus, a foreign language learning may provide a rich environment to deepen individuals' lingual and cultural identity and querying it in its relation with other cultures (Paluca Pop, 2016). 
Consequently, several policies were enacted in order to encourage more cooperation in the field of the development of teaching methods and evaluation of modern language learning. As well as producing a creative learning materials.

Intercultural competence can be embedded into education in several ways: whole school approach, cross curricular theme, integrated in subjects as a transversal objective, particularly in language (mother tongue, bilingual and multilingual education) and it can be included through extra-curricular activities as well as pupil mobility programmes.

Nevertheless, Intercultural competence is better naturally nurtured through foreign language learning, so that teachers can provide students with a wide range of opportunities to communicate and interact with their counterparts from diverse backgrounds. The language dimension also presents in (Content and Language Integrated Learning approach) whereby an optional course offered with one subject taught in a foreign language, it is another face of the cross-curricular approach for intercultural learning.

Studies demonstrated that intercultural competence is an element of language learning in all countries, and initiatives in this field are supported as endeavours to enhance intercultural competence, whilst other studies stated that despite the widespread discourse about intercultural education, its implementation still limited to countries and not to others (Nusche, 2009).

\subsection{The role of foreign language teachers}

In answering the question: What improves intercultural education? Evidence shows that cultural and linguistic awareness which can be enhanced through language learning and other parts of the curriculum, along with teacher's positive attitudes and effective parents engagement in school activities, may have the greatest impact on promoting intercultural competence.

The Leaders' Agenda on education and culture) highlighted the importance of the acquisition of language(s) of the host country, and promoting intercultural skills, to integrate migrant students, in order to fulfil their needs and support them to become active citizens, therefore, it is utmost necessity to build teachers and other staff capacities to enhance their preparedness to effectively respond to multicultural diversity. (European council 2017:5) Evidence shows that teacher training and professional development is likely to enabling them to be more responsive to cultural diversity in their classrooms, hence, it is imperative that the intercultural dimension should be included in their curricula. Whereas other researchers have emphasized the necessity of introducing prospective teachers to a wide range of cultural diversity before taking part in the profession (Mongillo \& Holland, 2017).

These arguments could be supported by the findings of 2017 Eurydice survey on Citizenship Education at School in Europe, which revealed that despite the importance of citizenship education in promoting common values, approximately half countries in the EU haven't addressed it in initial teacher education, which led to a skill-gap in terms of creating a receptive learning environment for all diverse groups of students.

The 2018 council recommendations on key competences for lifelong including intercultural and multilingual competences, unveiled a number of actions that should be taken in order to nurture the key competences, incorporating a wide range of learning approaches, and boost mobility of teachers and learners alike, in addition to propose new measures for evaluation of these competences. 
Given that Teachers are the main asset who can realize the integration of all students in multicultural and diverse classes, therefore, particular attention should be placed on teacher training and preparation, to provide them with competences needed to be culturally conscious and efficaciously fulfill the diverse needs of students. A good practice can be learned from Finnish experience in National Core Curriculum (2016) where cultural and linguistic diversity are perceived as opportunities to be grasped through cross curricula language sensitivity. However, several European countries in their educational policies have so far viewed the heterogeneity from a deficit viewpoint.

The ultimate goal of European cooperation in education and training 2020 is to ensure: "(a) the personal, social and professional fulfilment of all citizens; (b) sustainable economic prosperity and employability, whilst promoting democratic values, social cohesion, active citizenship, and intercultural dialogue."

With that aspiration in mind the focus should be placed on making lifelong learning and mobility a reality, and improving the quality and efficiency of education and training, in addition to Promoting equity, social cohesion and active citizenship, as well as enhancing creativity and innovation, including entrepreneurship, at all levels of education and training.

Facilitating learning mobility for students and teachers alike one of actions to promote intercultural and multilingual competence, admitting the importance of education (including life-long learning) and culture for achieving competitiveness and inclusiveness within European societies, A number of steps were determined, including further enhancement of mobility, and Promote exchange across European high schools through mutual recognition and developing a new curricula, in addition to fostering multilinguism and facilitate students' engagement in cultural activities through a «European Student Card».

There is a consensus within the EU countries that intercultural training should be provided for all teachers in general and for language teachers in particular, in order to support students from different background. The view is that teachers who work with students without the language of instruction should be equipped with the skills necessary through in service training to be able to support them in the classroom, moreover, initial teachers programmes should be adapted to better prepare prospective teachers to deal with diversity within the classroom environment. Moreover, in many countries and cities in the EU, variant resources, networking, and training provided by specialized centers for teachers to support migrant children's learning.

Notwithstanding, a number of actions at policy making level should be taken in order to conform to the multilingual classrooms, a curriculum for language learning in ECEC as well as in primary and secondary education for second language learning is essential; in addition to the need of unbiased assessment tools for testing children without the language of instruction; and better initialize prospective teachers through a relevant curriculum to deal with multilingual classrooms. that can be facilitated by adopting CLIL and whole school approaches to learning cultural awareness through the curriculum including language learning; as well as Promote positive attitudes about the potential of migrant children.

It has been proven that in such, increasingly divergence European classrooms, pre and inservice teacher training programs are paramount to enable them to support learners from heterogeneous backgrounds. Though Diversity in ITE is addressed through specific programmes or dedicated courses and workshops offered occasionally, the integrated approach still more efficient, which encompasses different aspects of diversity in transversal modules introduced within all ITE degree programmes, therefore, teachers effectively engage 
in developing innovative curricula, pedagogical practices and tools. It has been recommended to adapt the competence frameworks for teachers and ITE to include competences related to diversity, in addition to promote more empirical evidence on the role of ITE in preparing student teachers for diversity in Europe ((PPMI) 2017:7) Nonetheless, it seems that the practices in initial teacher programmes still based on the notion that cultural issues are the responsibility of the language department rather than a transversal topic that should be integrated into all disciplines (Ostermark, 2009).

The European profile for language teaching, which serve as a guidance to improve language teacher education programmes, expresses the critical role of foreign language teachers in achieving the EU common goals to reinforce plurilingualism among EU citizens. .

The profile explicitly reflect the interconnected relationship between foreign language learning and culture, through identifying a number of vital skills to be addressed in foreign language teacher training, in order to be aware of the dynamics of intercultural environment, and appreciate the variety of languages and cultures, as well as profoundly understand the significant role of teaching and learning foreign language and culture.

Moreover, the profile defines the strategies that can facilitate the acquisition of these skills, which include practical teaching experience in bilingual classrooms, and engaging in mobility programmes to spend a period in another country, thus, multicultural and multilingual settings are realistically experienced, and consequently a non-judgmental mindset might be nurtured. This can be also achieved through a continuous context-sensitive process, along with relevant learning materials and cross-curriculum approach, as well as networking and fellowship opportunities.

Practitioners advocate the experiential learning approach of D.A. Kolb to better promote intercultural competence through different practical activities, as embedding ICL into the curriculum cannot stand alone without adopting innovative approaches for its transmission.

It has been demonstrated that the remarkable role of intercultural competence is highly recognized at all levels in the EU, however, integrating and assessing it in initial teacher education and lifelong learning remains disparate. Accordingly, There is an insist need to assess the capabilities of language teachers to integrate and preserve the cultural dimension in their educational practices (Garrido \& lvarez, 2006).

While there is a wide consensus in Europe on Envisaging Intercultural competence as part of language learning, therefore embedded it into initial foreign language teacher education, it is often seen as a cross-cutting principle that should be addressed in all subjects. Thence, it is recommended to embed mobility programmes into all initial teacher and continuous professional development programmes, besides fostering the whole school approach in order to harness the potential that can be gained from the collaboration between all stakeholders including teachers, SPs, parents, students, and the wider community organizations (Hoffmann \& Briga, 2018).

It has been evident that many European countries provide student teachers with training programmes on diversity to prepare them for their future role in order to better respond to children's needs (Janta \& Harte 2016). However, countries are vary in terms of offering intercultural teacher education and training, which is reflected in different ways in the teacher competence framework for initial teacher education (Eurydice, 2019).

If EU member states are about to successfully implement intercultural education, institutional changes must be made, including changes in the curriculum and teaching 
materials; the expectations, attitudes and behaviours of teachers and the goals and culture of the school (Janta \& Harte, 2016).

\section{Conclusion}

In this study, it was aimed to find out how the education policy in Europe since Paris declaration in 2015 have addressed intercultural communication in its relation with foreign language teaching, it was not meant to compare policies or seek their evolvement, rather, the aim was to investigate whether or not these policies recognized the role of foreign language teaching in enhancing intercultural communication, and what the characteristics of these policies.

The documents' analysis has revealed that the heterogeneity of European societies played a decisive role in determining educational policies in general and those relevant to intercultural and plurilingual dimensions in particular, striving to effective inclusion of migrants into schools and society that predominated over most policies, in addition to raising individual competitiveness and employability, as well as realizing European identity as a leading influential global nation.

It can be concluded that Intercultural and Multilingual competences are interconnected in the vast majority of EU educational policies, whereby the language dimension alongside with intercultural education is a constant feature of all educational policies aiming at effective inclusion of migrants.

In other words, the emphasis on foreign language education is often companied with intercultural communicationldialogue in the context of integration and achieving social cohesion as well as expanding opportunities in order to ensure more prosperity, whereby the acquisition of two languages in addition to the mother tongue is a common ambition.

The main concentration in regard to foreign language is placed on preparing and developing teachers' capacities to be able to deal with diversity, along with providing proper curricula, this concern has mentioned repeatedly, which may draw attention to a potential defect in the implementation of these policies, particularly since the European Union confirms that its role is complementary to the national level actions, which have been reported to be inconsistent.

Moreover, although intercultural and multilingual competences are targeted in most policies, so far, there is no clear direction of their implementation at the national level.

\subsection{Implications}

While there are a plenty of studies on intercultural and multilingual educational policies in Europe, However, this study can be considered as intrinsic addition to the qualitative research on most recent educational policies in their role in promoting intercultural and multilingual education, However, it is an endeavour to shed light on potential gaps that may hinder the realizing of educational goals as well as paving the way for further research on the implementation of these policies.

It has been suggested that more empirical research is needed on the effectiveness of these policies and their implementation at the national level. 


\section{References}

Achaeva, M., Daurova, A., Pospelova, N., \& Borysov, V. (2018). Intercultural education in the system of training future teachers. Journal of Social Studies Education Research, 9(3), 261-281.

Agustin, O. G. (2012). Visions of the council of Europe and the European Commission for a Post-Multiculturalist Era. Retrieved from http://mail.immi.se/intercultural/nr29/garcia.html on 27 May 2019.

Arslan, H., \& Raţa, G. (Eds.). (2013). Multicultural education: from Theory to Practice. US: Cambridge Scholars Publishing.

Beacco, J. C., \& Byram, M. (2007). From linguistic diversity to plurilingual education: Guide for the development of language education policies in Europe. Strasbourg, France: Council of Europe Publishing.

Beacco, J. C., Byram, M., Cavalli, M., Coste, D., Cuenat, M. E., Goullier, F., \& Panthier, J. (2016). Guide for the development and implementation of curricula for plurilingual and intercultural education. Council of Europe.

Cetinavci, R. (2011). Intercultural communicative competence in English (foreign) language teaching and learning. Mediterranean Journal of Humanities, 59-71.

Climent-Ferrando, V. (2016). Linguistic Neoliberalism in the European Union: Politics and Policies of the EU's Approach to Multilingualism.

Coste, D., \& Simon, D. L. (2009). The plurilingual social actor: Language, citizenship and education. International Journal of Multilingualism, 6(2), 168-185.

Coste, D., Moore, D., \& Zarate, G. (2009). Plurilingual and pluricultural competence. Language Policy Division. Strasbourg: Council of Europe.

Council of Europe. (2001). Common European Framework of Reference for Languages: Learning, teaching, assessment. US: Cambridge University Press.

Crowley, P. M. (2017). Crossing the Atlantic: Comparing the European Union and Canada. US: Routledge.

Cullen, H. (1996). From migrants to citizens? European Community policy on intercultural education. International \& Comparative Law Quarterly, 45(1), 109-129.

Diaconescu, R., Stanciugelu, S., Copot, D., Vatavu, G., Pop, I., \& Rusu, I. (2013). State and private sector involvement in developing and promoting cultural and religious heritage. European Journal of Science and Theology, 9(3), 207-217.

Ebersold, S., Watkins, A., Oskarsdottir, E., \& Meijer, C. J. (2019). Financing inclusive education to reduce disparity in education: Trends, issues and drivers. US: The SAGE Handbook of Inclusion and Diversity in Education.

Feliu, P. G., Espona-Barcons, B., \& Essomba Gelabert, M. A. (2016). How is Europe facing diversity in education? Comparing national policies on the education of children and youngsters with a migrant background. Current Politics \& Economics of Europe, 27(34), 375-392.

Garrido, C., \& Alvarez, I. (2006). Language teacher education for intercultural understanding. European Journal of Teacher Education, 29(2), 163-179. 
Garrido, C., \& Alvarez, I. (2006). Language teacher education for intercultural understanding. European Journal of Teacher Education, 29(2), 163-179.

Genova, M. (2019). Intercultural and Civic Education-Good Practices. Професионално образование, 21(2), 185-199.

Giorgis, P. (2018). The spaces in between: Foreign language education as critical and intercultural education. Taboo: The Journal of Culture and Education, 17(3), 55-72.

Harte, E., Herrera, F., Stepanek, M., \& Rand, E. (2016). Education of EU Migrant children in EU member states. RAND.

Hoffmann, W., \& Briga, E. (2018). A brief overview on intercultural learning in initial teacher education and continuing professional development for teachers of upper secondary schools, intercultural learning for pupils and teachers project, funded by European commission. Retrieved from http://intercultural-learning.eu/wpcontent/uploads/2017/01/ICL-in-ITE- on 22 June 2019.

Huber, J. (2012). Intercultural competence for all: preparation for living in a heterogeneous world (Vol. 2). Council of Europe.

Janta, B., \& Harte, E. (2016). Education policy responses for the inclusion of migrant children in Europe. Retrieved from https://www.rand.org/pubs/research_reports/RR1655.html on 22 June 2019.

Jeoffrion, C., Marcouyeux, A., Starkey-Perret, R., Narcy-Combes, M. F., \& Birkan, I. (2014). From multilingualism to plurilingualism: University students' beliefs about language learning in a monolingual context. Language, Culture and Curriculum, 27(1), 8-26.

Meer, N., \& Modood, T. (2012). How does interculturalism contrast with multiculturalism?. Journal of Intercultural Studies, 33(2), 175-196.

Meijer, C. J., \& Watkins, A. (2019). Financing special needs and inclusive education-from Salamanca to the present. International Journal of Inclusive Education, 1-17.

Mongillo, G., \& Holland, K. F. (2016). Elementary teachers' perspectives on the use of multicultural literature in their classrooms. Language and Literacy, 18(3), 16-32.

Ortega, Y. (2018). Plurilingualism in the new era: A conversation with Enrica Piccardo. Argentinian Journal of Applied Linguistics, 6(1), 75-91.

Ostermark, E. (2009). Language teacher education in Finland and the cultural dimension of foreign language teaching-a student teacher perspective. European Journal of Teacher Education, 32(4), 401-421.

Pop, R. (2016). Foreign language learning in today's multicultural and multilingual classrooms. Studia Universitatis Babes-Bolyai-Philologia, 61(3), 231-238.

Pena-Díaz, C. (2019). Child language brokering: Challenges in Spanish intercultural education. Intercultural Education, 30(4), 368-382.

Piccardo, E. (2017). Plurilingualism as a catalyst for creativity in superdiverse societies: A systemic analysis. Frontiers in Psychology, 8, 1-13

Sabato, S., \& Vanhercke, B. (2017). Towards a European Pillar of Social Rights: From a preliminary outline to a Commission Recommendation. Social Policy in the European Union: State of the Play, 73-96. 
Staiger, U. (2009). New agendas? Culture and citizenship in EU policy. International Journal of Cultural Policy, 15(1), 1-16.

Toggenburg, G. N. (2004). United in diversity': Some thoughts on the new motto of the enlarged Union. In Il Mercator International Symposium: Europe 2004: A new framework for all languages (pp. 27-28).

\section{Webliography:}

https://ec.europa.eu/education/education-in-the-eu/council-recommendation-on-commonvalues-inclusive-education-and-the-european-dimension-of-teaching_en

https://www.coe.int/en/web/language-policy/plurilingual-education

https://eacea.ec.europa.eu/national-policies/eurydice/home en

https://www.consilium.europa.eu/en/policies/tallinn-leaders-agenda/

https://op.europa.eu/en/publication-detail/-/publication/404b34d1-ef63-11e6-8a35-

01aa75ed71a1

https://eur-lex.europa.eu/legal-content/EN/TXT/?uri=CELEX\%3A52016DC0941 